\title{
Taxonomia de Anisepyris Kieffer (Hymenoptera, Bethylidae) da Mata Atlântica Brasileira
}

\author{
Lucyane M. dos Santos ${ }^{1} \&$ Celso O. Azevedo ${ }^{2}$
}

${ }^{1}$ PPG-Biologia Animal, Universidade Federal do Espírito Santo, Av. Marechal Campos 1468, 29.040-090 Vitória-ES, Brasil. Bolsista CAPES. lucyanes@bol.com.br

${ }^{2}$ Departamento de Biologia, UFES. Pesquisador do CNPq. bethylidae@gmail.com

\begin{abstract}
Taxonomy of Anisepyris Kieffer (Hymenoptera, Bethylidae) from Brazilian Atlantic rain forest. Species of Anisepyris Kieffer, 1905, from 31 sites along the Atlantic rain forest were studied. A. basilongus Santos sp. nov., A. foveapertus Santos sp. nov., A. artus Santos sp. nov., A. basilargus Santos sp. nov., A. cepus Santos sp. nov. and A. ramosus Santos sp. nov. were described and illustrated. Sixteen previously described species were analyzed and had their distribution broadened: A. amazonicus Westwood, 1874, A. bifidus Evans, 1966, A. bipartitus Santos \& Azevedo, 2000, A. delicatus Evans, 1966, A. dentatus Santos \& Azevedo, 2000, A. divisus Santos, 2002, A. inconspicuus Santos, 2002, A. lobatus Santos \& Azevedo, 2000, A. longimerus Santos \& Azevedo, 2000, A. nigripes Evans, 1966, A. proteus Evans, 1966, A. rotundus Santos, 2002, A. similis Santos \& Azevedo, 2000, A. triangularis Moreira \& Azevedo, 2003, A. trinitatis Evans, 1966 and A. tuberosus Santos \& Azevedo, 2000. Anisepyris bipartitus, A. dentatus, A. similis and A. trinitatis are recorded for the first time from the Atlantic rain forest.
\end{abstract}

KEYWORDS. Biodiversity; new species; parasitoid; systematic.

RESUMO. Taxonomia de Anisepyris Kieffer (Hymenoptera, Bethylidae) da Mata Atlântica Brasileira. Foram estudadas as espécies de Anisepyris Kieffer, 1905, coletadas em 31 localidades ao longo da Mata Atlântica Brasileira. Foram descritas e ilustradas as seguintes espécies novas: A. basilongus Santos sp. nov., A. foveapertus Santos sp. nov., A. artus Santos sp. nov., A. basilargus Santos sp. nov., A. cepus Santos sp. nov. e A. ramosus Santos sp. nov.. Foram examinados espécimes adicionais de dezesseis espécies previamente descritas: A. amazonicus Westwood, 1874, A. bifidus Evans, 1966, A. bipartitus Santos \& Azevedo, 2000, A. delicatus Evans, 1966, A. dentatus Santos \& Azevedo, 2000, A. divisus Santos, 2002, A. inconspicuus Santos, 2002, A. lobatus Santos \& Azevedo, 2000, A. longimerus Santos \& Azevedo, 2000, A. nigripes Evans, 1966, A. proteus Evans, 1966, A. rotundus Santos, 2002, A. similis Santos \& Azevedo, 2000, A. triangularis Moreira \& Azevedo, 2003, A. trinitatis Evans, 1966 e A. tuberosus Santos \& Azevedo, 2000, incluindo citações geográficas novas e suas variações taxonômicas, sendo o primeiro registro de A. bipartitus, A. dentatus, A. similis e A. trinitatis para a Mata Atlântica.

PALAVRAS-CHAVE. Biodiversidade; espécie nova; parasitóide; sistemática.

Anisepyris Kieffer, 1905 foi descrito com base em quatro espécies da América, as quais apresentavam mandíbula com cinco dentes, antenas com 13 segmentos e disco pronotal marginado anterior e lateralmente. Kieffer (1905) observou a similaridade de Anisepyris com Epyris Westwood, 1832 quanto à forma externa do corpo e neste mesmo ano transferiu seis espécies de Epyris para Anisepyris e elegeu E. amazonicus Westwood, 1874 como espécie-tipo do gênero. Evans (1966) revisou o gênero, quando elaborou chaves de identificação para machos e fêmeas, e propôs a divisão das espécies em oito grupos de espécies, a saber: grupo aeneus, amazonicus, aurichalceus, columbianus, excisus, occidentalis, proteus e venustus.

Anisepyris pertence à subfamília Epyrinae, ocorre desde os Estados Unidos até o sul do Brasil, incluindo algumas ilhas do Caribe e Golfo do México (Evans, 1959). Até a realização deste estudo, o gênero continha 92 espécies, sendo que 87 ocorrem na região neotropical e 25 na Mata Atlântica.

\section{MATERIALEMÉTODOS}

O material analisado é proveniente principalmente dos projetos: "Riqueza de Hymenoptera e Isoptera ao longo de um gradiente latitudinal da Mata Atlântica Brasileira", apoiado pelo programa BIOTA/FAPESP, que realizou coletas utilizando-se de armadilha Malaise, armadilha Möricke e varredura de vegetação; "Biodiversidade de um Trecho de Mata Atlântica de Vitória”, apoiado pelo FACITEC, utilizandose de varredura de vegetação e "Biodiversidade da Mata Atlântica do Espírito Santo", apoiado pelo CNPq, utilizandose de armadilha Malaise. O material do primeiro projeto pertence ao Museu de Zoologia da Universidade de São Paulo (MZSP, C.R.F. Brandão) e dos demais à Universidade Federal do Espírito Santo, Brasil (UFES, C.O. Azevedo).

A identificação das espécies seguiu a classificação proposta por Evans (1966). Os exemplares de algumas espécies foram comparados com material-tipo depositado na California 
Academy of Sciences, E.U.A. (CASC, R. L. Zuparko), Canadian National Collection of Insects, Canadá (CNCI, J. T. Huber), Instituto Nacional de Pesquisas da Amazônia, Brasil (INPA, J.A. Rafael), Museum of Comparative Zoology, E.U.A. (MCZH, P. Perkins \& S. Cover), Museu Paraense Emílio Goeldi, Brasil (MPEG, O. T. Silveira), Oxford University Museum of Natural History, Inglaterra (OXUM, J. Hogan) e Universidade Federal do Espírito Santo, Brasil (UFES, C.O. Azevedo).

Os termos das estruturas corporais adotados seguem Evans (1966) e Azevedo (1999). As medidas usadas foram: DAO, diâmetro do ocelo anterior; HE, altura do olho; LFW, comprimento da asa anterior; LH, comprimento da cabeça; OOL, linha ocelo-ocular - mínima distância do olho para o ocelo lateral; VOL, linha vértice-ocular - distância do topo do olho à crista do vértice, medida em vista lateral; WF, largura da fronte; WH, largura da cabeça; WOT, largura do triângulo ocelar; comprimento e largura do disco pronotal; comprimento e largura do disco propodeal; comprimento do corpo. Os termos de textura do integumento seguem Harris (1979). As ilustrações foram baseadas nos holótipos e tiveram a pubescência regular suprimida.

\section{RESULTADOS EDISCUSSÃO}

Foram reconhecidas 22 espécies, sendo seis espécies novas e 16 espécies previamente descritas, das quais quatro espécies têm seu primeiro registro para Mata Atlântica. Desta forma, o gênero passa a ter 98 espécies descritas, sendo 93 neotropicais. O número de espécies registradas para Mata Atlântica passa de 25 para 35.

\section{Lista de espécies estudadas}

\section{Grupo aeneus}

1. Anisepyris basilongus Santos sp. nov. Macho. Brasil (ES)

2. Anisepyris longimerus Santos \& Azevedo, 2000. Macho. Brasil (ES, SP, PR)

\section{Grupo amazonicus}

3. Anisepyris amazonicus Westwood, 1874. Macho, Fêmea. Brasil (AC, AM, PA, MA, MT, SE, BA, ES, RJ)

4. Anisepyris foveapertus Santos sp. nov. Fêmea. Brasil (BA, ES)

\section{Grupo columbianus}

5. Anisepyris nigripes Evans, 1966. Macho. Guiana, Equador, Brasil (AM, AP, PA, MA, ES, SC).

\section{Grupo proteus}

6. Anisepyris artus Santos sp. nov. Macho. Brasil (ES)

7. Anisepyris basilargus Santos sp. nov. Macho. Brasil (ES)

8. Anisepyris bifidus Evans, 1966. Macho. Panamá, Equador, Brasil (AM, PA, BA, ES, RJ, SP, PR) e Peru.

9. Anisepyris bipartitus Santos \& Azevedo, 2000. Macho. Brasil (AM, PA, MT, AL)

10. Anisepyris cepus Santos sp. nov. Fêmea. Brasil (ES)
11. Anisepyris delicatus Evans, 1966. Macho. Guiana, Brasil (ES, RJ, PR, SC).

12. Anisepyris dentatus Santos \& Azevedo, 2000. Macho. Brasil (PA, PE, BA, ES, PR)

13. Anisepyris divisus Santos, 2002. Macho. Brasil (ES)

14. Anisepyris inconspicuus Santos, 2002. Macho. Brasil (ES)

15. Anisepyris lobatus Santos \& Azevedo, 2000. Macho. Brasil (PE, BA, ES, PR)

16. Anisepyris proteus Evans, 1966. Macho, Fêmea. Brasil (DF, ES, MG, RJ, SP, PR, SC)

17. Anisepyris ramosus Santos sp. nov. Macho. Brasil (AL, SE, BA)

18. Anisepyris similis Santos \& Azevedo, 2000. Macho. Brasil (AM, PA, SE, BA, RJ)

19. Anisepyris triangularis Moreira \& Azevedo, 2003. Macho. Brasil (AL, BA, ES)

20. Anisepyris trinitatis Evans, 1966. Macho. Guiana, Brasil (PA, MA, AL, MT, GO), Trinidad.

21. Anisepyris tuberosus Santos \& Azevedo, 2000. Macho. Brasil (AL, BA, ES)

Grupo venustus

22. Anisepyris rotundus Santos, 2002. Fêmea. Brasil (BA, ES, RJ, SP)

\section{Grupoaeneus \\ Anisepyris basilongus Santos sp. nov.}

(Figs. 1-5)

Descrição. Holótipo: macho; comprimento 6,50 mm; LFW $3,50 \mathrm{~mm}$.

Coloração. Cabeça e dorso torácico pretos, com reflexos verdes e dourados; metassomo castanho-escuro quase preto; clípeo preto; mandíbula, escapo, coxas anterior e posterior, fêmures castanho-escuros quase pretos; pedicelo, flagelo, coxa mediana e tíbias castanho-escuros, palpos, trocânteres e tarsos castanho-claros; asa anterior subialina; nervuras castanho-escuras.

Cabeça (Fig. 1). Mandíbula com cinco dentes apicais, o inferior pouco maior (Fig. 2). Clípeo com lobo mediano angulado, carena mediana alta e arqueada em perfil. Quatro primeiros segmentos antenais na proporção de 35:10:7:23, relação comprimento/largura dos segmentos antenais: III 0,87x; $\mathrm{III}+\mathrm{IV}=3,00 \mathrm{x} ; \mathrm{IV}=2,30 \mathrm{x} ; \mathrm{XI}=2,57 \mathrm{x}$. Escrobo antenal com carena pouco definida, não atingindo margem interna do olho. Olho com cerdas longas. Fronte coriácea com pontos pequenos, separados 1-3x seus diâmetros; WH 1,04x LH; WF 0,59x WH; WF 1,14x HE; WOT 1,05x OOL. Vértice amplamente arredondado, canto arredondado; carena occipital não visível em vista dorsal; VOL 0,14x HE.

Mesossomo (Fig. 1). Dorso torácico pouco coriáceo e brilhante, com pontos pequenos, distintos, separados 2-4x seus diâmetros. Disco pronotal 2x mais largo que longo; carena transversal anterior bem distinta e elevada; carena lateral ausente; margem posterior do disco pronotal acompanhada de série de fóveas. Notáulice incompleta anterior e 
posteriormente. Disco propodeal 1,60x mais largo que longo, com cinco carenas discais distintas e duas carenas adicionais tênues paralelas à mediana; canto posterior foveolado, lateral do propódeo predominantemente estrigulada e coriácea; declividade estrigulada, carena mediana incompleta ventralmente. Mesopleura brilhante, pouco coriácea, com pontos pequenos e esparsos; fóvea inferior com margem superior aberta e margem inferior fechada (Fig. 3). Fêmur anterior 2,60x mais longo que largo. Tíbia mediana sem espinhos dorsais. Garras tarsais trífidas.

Genitália (Figs. 4-5). Parâmero longo, 2,6x o basiparâmero, $3,6 \mathrm{x}$ mais longo que largo; base muito estreitada e longa; margem apical, pilosa, larga e arredondada; margem dorsal com chanfro próximo ao ápice; margem ventral pouco convexa; cúspide com ramo dorsal largo, estreitado no ápice; ramo ventral digitiforme; dígito tão longo quanto a cúspide; edeago com ápice arredondado, tão alto quanto o ápice do dígito; metade basal dilatada; metade apical estreita.

Material Examinado. Holótipo: macho. BRASIL, Espírito Santo, Santa Maria de Jetibá, Fazenda Clarindo Kruger, 2004'27,9"S 404 '51,3"O, 29.xi-06.xii.2002, armadilha Malaise, M. T. Tavares, C. O. Azevedo \& eq. col. (UFES). Parátipos: BRASIL, Espírito Santo, 2 machos, mesmos dados do holótipo (UFES); Santa Maria de Jetibá, Fazenda Paulo Seick, $20^{\circ} 02^{\prime} 31,1^{\prime \prime S} 40^{\circ} 41^{\prime} 51,3$ "O, 3 machos, 29.xi06.xii.2002, 1 macho, 06-13.xii.2002, armadilha Malaise, M. T. Tavares, C. O. Azevedo \& eq. col. (UFES); 1 macho, Santa Teresa, Estação Biológica de Santa Lúcia, 1958'18,5"S 40³2'07,6"O, 0609.iv.2001, armadilha Malaise, C. O. Azevedo \& eq. col. (MZSP).

Variações: cabeça e dorso torácico com reflexos verdes mais fracos; fronte fracamente coriácea; manchas douradoazuladas na lateral do propódeo; parâmero com ápice levemente mais arredondado; cúspide com a invaginação rasa dividindo ramos dorsal e ventral; cúspide com os ramos dorsal e ventral mais separados; ramo dorsal da cúspide pouco mais largo.

Discussão. Esta espécie é semelhante a A. punctatus Santos \& Azevedo, 2000 por ter mandíbula com cinco dentes, clípeo com lobo mediano angulado, escrobo antenal com carena tênue, índices WH/LH, WF/WH, WF/HE, WOT/OOL, $\mathrm{VOL} / \mathrm{HE}$ semelhantes, disco pronotal sem carena lateral, mas difere desta por ter fronte coriácea; parâmero mais largo e com base longa, dilatado na porção mediana, com um chanfro na margem dorsal próximo ao ápice e cúspide com margem ventral arredondada próximo à base, enquanto A. punctatus tem parâmero com base longa, porção mediana uniforme, ápice arredondado, cúspide com ramo dorsal estreito e margem ventral formando uma angulação acentuada próxima à base.

Distribuição. Brasil (Espírito Santo).

Etimogenia. Do latim basis: base + longus: longo, em referência à base longa do parâmero.

\section{Anisepyris longimerus Santos \& Azevedo, 2000}

Esta espécie é registrada pela primeira vez para o Paraná e são ampliados os dados de distribuição para o Espírito Santo. Nesta série, foram encontradas as seguintes variações: manchas douradas próximas aos ocelos, clípeo com lobo mediano angulado, fóvea inferior da mesopleura com margem superior aberta, parâmero estreito, 4,07-4,15x mais longo que largo.

Material Examinado. BRASIL, Espírito Santo, 1 macho, Santa Maria de Jetibá, Fazenda Paulo Seick, 2002'31,1"S 4041'51,3"O, 29.xi-06.xii.2002, armadilha Malaise, M. T. Tavares, C. O. Azevedo \& eq. col. (UFES); Paraná, 2 machos, Morretes, Parque Estadual do Pau Oco, 25³4'27,5"S 4853'33"O, 07-13.iv.2002, armadilha Malaise, M. T. Tavares \& eq. col. (MZSP, UFES).

\section{Grupo amazonicus Anisepyris amazonicus Westwood, 1874.}

Esta espécie é registrada pela primeira vez para Sergipe, Bahia e Rio de Janeiro. Os exemplares fêmeas foram comparados com o holótipo Epyris amazonicus (fêmea) depositado no OXUM e com exemplares de Manaus (AM) do INPA. Nesta série, foram encontradas as seguintes variações, fêmeas: cabeça e dorso torácico com reflexos metálicos verde-claros e dourados, reflexos roxo-azulados e roxo-avermelhados na cabeça e mesossomo, fêmur mediano castanho-avermelhado e fóvea inferior da mesopleura com margem superior aberta por uma distância pequena. Machos: um exemplar de Sooretama com WH=1,03x LH; WF 0,57x WH; WF 1,06x HE; WOT 0,81x OOL, cabeça e dorso torácico com reflexos verde-escuros e dourados, carena do escrobo antenal não atingindo margem interna do olho, fóvea inferior da mesopleura com margem superior aberta na porção anterior, parâmero 4,30x mais longo que largo, parâmero castanho-escuro e cúspide com ápice do ramo dorsal mais estreito ou cúspide pouco maior que dígito e edeago. A variação da fóvea inferior da mesopleura com margem superior aberta no terço mediano, observada em machos e fêmeas analisados por Santos \& Azevedo (2000), foi também vista em alguns exemplares machos de Crasto, Porto Seguro e Nova Iguaçu.

Material Examinado. BRASIL, Sergipe, Santa Luzia do Itanhy, Crasto, $11^{\circ} 22^{\prime} 41,0^{\prime \prime S} 37^{\circ} 24^{\prime} 54,1$ "O, 29.vii-05.viii.2001, 1 fêmea, armadilha Möricke, M. T. Tavares \& eq. col. (MZSP), 1 macho, armadilha Malaise, 3 machos, armadilha Möricke, $11^{\circ} 22^{\prime} 40,5^{\prime \prime} \mathrm{S}$ $37^{\circ} 25^{\prime} 00,6^{\prime \prime O}$, (MZSP, UFES); Bahia, 1 fêmea, Mata de São João, Reserva de Sapiranga, 12³3'19,5"S 3803'10,1"O, 19-26.vii.2001, armadilha Möricke, M. T. Tavares \& eq. col (MZSP, UFES), 1 fêmea, $12^{\circ} 33^{\prime} 27,7^{\prime \prime S ~ 38 \circ 03 ' 06,6 " O, ~(M Z S P), ~} 1$ fêmea, 12³3'44,2"S $38^{\circ} 03^{\prime} 04,1^{\prime \prime O}$, (MZSP), 1 macho, armadilha Malaise, 12³3'36,4"S $38^{\circ} 02^{\prime} 57,2^{\prime \prime O}$, (MZSP); Bahia, Porto Seguro, Estação Ecológica do Pau Brasil, 16²3'17,6"S 39¹0'55"O, 16-21.v.2002, 1 fêmea, 5 machos, armadilha Möricke, 1 fêmea, armadilha Malaise, 1 fêmea, 2 machos, varredura, C. O. Azevedo \& eq. col. (MZSP, UFES); Ilhéus, Mata Esperança, $14^{\circ} 46^{\prime}$ 'S 39 $04^{\prime}$ W, 15-21.v.2002, 2 fêmeas, 1 macho, armadilha Malaise, 1 macho, armadilha Möricke, Penteado-Dias \& eq. col. (MZSP, UFES); Espírito Santo, Sooretama, Reserva Biológica de Sooretama, 1900'11,5"S 4007'08"O, 21-27.iii.2002, 1 fêmea, armadilha Möricke, 1 macho, armadilha Malaise, C. O. Azevedo \& eq. col. (MZSP), 2 machos, Santa Teresa, Estação Biológica de Santa Lúcia, $19^{\circ} 58^{\prime} 25,2^{\prime \prime S} 40^{\circ} 31^{\prime} 44,6$ "O, 07-11.iv.2001, varredura, C. O. Azevedo \& eq. col. (MZSP, UFES); Pancas, 1 macho, Fazenda Juliberto Stur, $19^{\circ} 13^{\prime} 10,5^{\prime \prime S} 40^{\circ} 46^{\prime} 23,8^{\prime \prime} \mathrm{O}, 31 . i-07 . i i .2003$, armadilha Malaise, M. T. Tavares, C. O. Azevedo \& eq. col. (UFES); Santa Maria de Jetibá, 1 macho, Fazenda Paulo Seick, 2002'31,1"S 4041'51,3"O, 29.xi06.xii.2002, armadilha Malaise, M. T. Tavares, C. O. Azevedo \& eq. 
col. (UFES); Rio de Janeiro, Nova Iguaçu, Reserva Biológica do Tinguá, 22³4'40"S 43²6’08"O, 05-12.iii.2002, 1 fêmea, armadilha Möricke, STP Amarante \& eq. col. (MZSP), 4 machos, $22^{\circ} 34^{\prime} 34^{\prime \prime} \mathrm{S} 43^{\circ} 26^{\prime} 05^{\prime \prime} \mathrm{O}$,

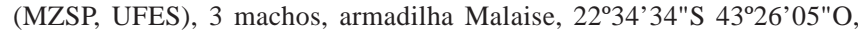
(MZSP).

\section{Anisepyris foveapertus Santos sp. nov. (Figs. 6-8)}

Descrição. Holótipo: fêmea; comprimento 8,30 mm; LFW 4,70mm.

Coloração. Cabeça e dorso torácico pretos, com reflexos verde-oliva e dourados; disco propodeal preto; metassomo, clípeo e mandíbula castanho-escuros, dentes castanhoavermelhados; coxa anterior preta; coxas mediana e posterior castanho-escuras quase pretas; escapo, palpos e tarsos castanho-claros; pedicelo, flagelo, trocânteres, fêmures anterior e mediano castanho-avermelhados, posterior castanho-escuro quase preto; asa anterior fortemente subialina, nervuras castanho-claras.

Cabeça (Fig. 6). Mandíbula com quatro dentes apicais largos, três superiores curtos (Fig. 7). Clípeo com lobo mediano subangulado, região mediana elevada, carena média alta, reta e horizontal vista em perfil. Quatro primeiros segmentos antenais na proporção de 42:11:10:15, relação comprimento/ largura dos segmentos antenais: III 1,00x; III + IV=2,78x; IV= $1,36 \mathrm{x} ; \mathrm{XI}=1,50 \mathrm{x}$. Escrobo antenal com carena inconspícua. Olho com cerdas longas. Fronte fortemente coriácea com pontos grandes, densos, separados 0,0-0,5x seus diâmetros; WH 1,12x LH; WF 0,61x WH; WF 1,22x HE; WOT 0,47x OOL. Vértice reto, canto arredondado; carena occipital não visível em vista dorsal; VOL 0,33x HE. Têmpora divergente anteriormente.

Mesossomo (Fig. 6). Disco pronotal e mesoscuto coriáceos, pouco brilhantes, pontos muito mais esparsos que os da fronte. Disco pronotal 1,43x mais largo que longo; carena transversal anterior conspícua; carena lateral ausente; margem posterior do disco pronotal acompanhada de série de fóveas. Notáulice incompleta posteriormente. Disco propodeal 1,55x mais largo que longo, com cinco carenas discais e duas carenas adicionais paralelas à mediana, canto posterior foveolado; lateral do propódeo predominantemente estrigulada e coriácea; declividade coriácea na porção superior e estrigulada na inferior, carena mediana completa. Mesopleura brilhante, coriácea, com reflexos verdes e dourados; fóvea inferior com margem superior aberta e margem inferior fechada (Fig. 8). Fêmur anterior 2,33x mais longo que largo. Tíbia mediana sem espinhos dorsais. Garras tarsais trífidas.

Material Examinado. Holótipo: fêmea. BRASIL, Bahia, Porto Seguro, Estação Ecológica do Pau Brasil, 16²3'17,6"S 39²10'55"O, 2O.v.2002, armadilha Möricke, C. O. Azevedo \& eq. col (MZSP). Parátipos: BRASIL, Bahia, 2 fêmeas, mesmos dados do holótipo, (MZSP, UFES); Espírito Santo, 1 fêmea, Sooretama, Reserva Biológica de Sooretama, $19^{\circ} 00^{\prime} 11,5^{\prime \prime S} 40^{\circ} 07^{\prime} 08^{\prime \prime} \mathrm{O}, 21-24 . i i i .2002$, armadilha Malaise C. O. Azevedo \& eq. col. (MZSP); 1 fêmea, Santa Maria de Jetibá, Fazenda Paulo Seick, 2002'31,1"S 4041'51,3"O, 29.xi06.xii.2002, armadilha Malaise, M. T. Tavares, C. O. Azevedo \& eq. col. (UFES).
Variações: cabeça e dorso torácico verde-claros com reflexos dourados fortes; palpos castanho-avermelhados; manchas coloração rosa-azulado nas laterais, na margem posterior do disco pronotal e na porção anterior da mesopleura; faixa amarela-avermelhada com dourado no mesoscuto, próxima à margem posterior do disco pronotal; metassomo preto, claro na metade distal.

Discussão. Esta espécie é semelhante a A. amazonicus Westwood, 1874, do Brasil por ter comprimentos corporais aproximados, colorações da cabeça e dorso torácico pretos com reflexos verdes e dourados fortes, cabeça mais larga que longa e mandíbula com quatro dentes e dela difere por ter clípeo com lobo mediano subangulado, fronte com pontos grandes e contíguos próximos à margem anterior, vértice reto e fóvea inferior da mesopleura com margem superior claramente aberta enquanto $A$. amazonicus tem clípeo com lobo mediano subtruncado, fronte fracamente coriácea com pontos menores e mais esparsos, vértice amplamente redondo e fóvea inferior da mesopleura com margem superior completamente fechada.

Distribuição. Brasil (Bahia, Espírito Santo).

Etimogenia. Do latim foveapertus, em referência à fóvea inferior da mesopleura que é aberta na margem superior.

\section{Grupo columbianus Anisepyris nigripes Evans, 1966}

Esta espécie tem seus dados ampliados para o Espírito Santo. Nesta série, foram encontradas as seguintes variações: cabeça e dorso torácico pretos, com reflexos dourados; mandíbula castanho-escura com dentes castanhoavermelhados; todos os exemplares desta série com asas anteriores hialinas, caráter observado por Santos \& Azevedo (2000) apenas em fêmeas, fronte fortemente coriácea, vértice levemente convexo, carena occipital não visível em vista dorsal, carena lateral do disco pronotal bastante forte, margem posterior do disco pronotal acompanhada de série de fóveas grandes, notáulice grossa.

Material Examinado. BRASIL, Espírito Santo, 3 machos, Sooretama, Reserva Biológica de Sooretama, 1900'11,5's 4007'08' O, 24-27.iii.2002, armadilha Malaise, C. O. Azevedo \& eq. col. (MZSP, UFES).

\section{Grupo proteus \\ Anisepyris artus Santos sp. nov. (Figs. 9-13)}

Descrição. Holótipo: macho; comprimento 4,98 mm; LFW $2,70 \mathrm{~mm}$.

Coloração. Cabeça e dorso torácico pretos, com reflexos verde-oliva e dourados; metassomo e clípeo pretos; mandíbula e escapo castanho-escuros; pedicelo e flagelo castanhoavermelhados; palpos castanho-claros; coxas castanhoavermelhadas exceto coxa anterior preta; trocânteres castanhoavermelhados; fêmures pretos; tarsos e tíbia anterior castanhoclaros; tíbias castanho-avermelhadas; asa anterior hialina; nervuras castanho-avermelhadas. 


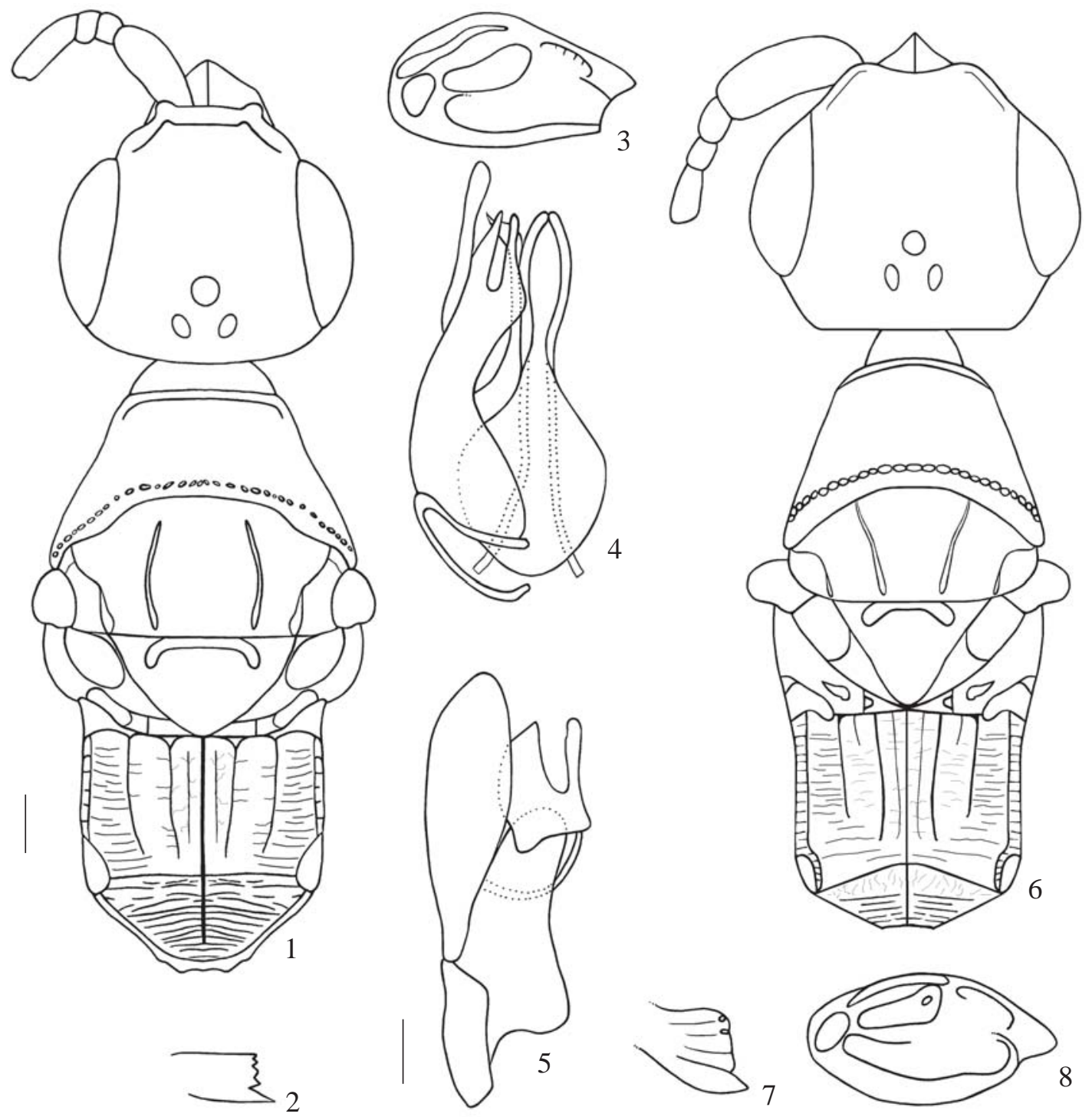

Figs. 1-8. Anisepyris basilongus Santos sp. nov., holótipo, macho. 1, cabeça e mesossomo, dorsal; 2, mandíbula, frontal; 3, mesopleura, lateral; 4-5, genitália, ventral e lateral. Figs. 6-8. A. foveapertus Santos sp. nov., holótipo, fêmea. 6, cabeça e mesossomo, dorsal; 7, mandíbula, frontal; 8 , mesopleura, lateral. (escalas: figs. $1-3=250 \mu \mathrm{m}$; figs. $4-5=100 \mu \mathrm{m}$; figs. $6-8=250 \mu \mathrm{m}$ ).

Cabeça (Fig. 9). Mandíbula com cinco dentes apicais aproximadamente do mesmo tamanho, exceto inferior, bem maior que demais dentes (Fig. 10). Clípeo com lobo mediano fortemente angulado, carena mediana alta e arqueada em perfil. Quatro primeiros segmentos antenais na proporção de 19:5:3:10, relação comprimento/largura dos segmentos antenais: III 0,60x; III + IV=2,33x; IV=1,67x; XI=2,50x. Escrobo antenal com carena muito tênue, não atingindo margem interna do olho. Olho com cerdas longas. Fronte coriácea com pontos pequenos e distintos, separados 1-4x seus diâmetros; WH 1,08x LH; WF 0,62x WH; WF 1,21x HE; WOT 0,72x OOL. Vértice quase reto, canto levemente arredondado; carena occipital pouco visível em vista dorsal; VOL 0,32x HE.

Mesossomo (Fig. 9). Dorso torácico levemente coriáceo e brilhante, com pontos distintos, separados 4-5x seus diâmetros; disco pronotal 2,23x mais largo que longo; carena transversal anterior distinta e elevada; carena lateral inconspícua; margem posterior do disco pronotal acompanhada de série de fóveas médias. Notáulice completa. Disco propodeal 1,60x mais largo que longo, com cinco carenas discais, duas carenas adicionais distintas paralelas à mediana a partir de $3 / 4$ do comprimento do disco e duas carenas adicionais inconspícuas paralelas à paramediana, canto posterior foveolado; lateral do propódeo predominantemente estrigulada; declividade estrigulada, carena mediana completa. Mesopleura brilhante, pouco coriácea, fóvea inferior com margem superior aberta e margem inferior fechada (Fig. 11). Fêmur anterior 2,31x mais longo que largo. Tíbia mediana sem espinhos dorsais. Garras tarsais trífidas.

Genitália. (Figs. 12, 13) parâmero longo, cerca de 2,00x basiparâmero, 3,33x mais longo que largo; base muito estreita; margem apical arredondada; margens dorsal e ventral paralelas e uniformes exceto metade basal da margem ventral; margens 
apical e dorsal pilosas; cúspide com ramo dorsal estreitado em direção ao ápice; ramo ventral digitiforme; dígito pouco mais longo que cúspide; edeago pouco menor que dígito; metade basal dilatada; metade apical estreita; margem apical arredondada.

Material Examinado. Holótipo: macho. BRASIL, Espírito Santo, Itarana, Fazenda Bom Destino, 1951'27"S 4054'51"O, 21-25.ii.2004, armadilha Malaise, B. C. Araújo col. (UFES). Parátipos: BRASIL, Espírito Santo, 1 macho, mesmos dados do holótipo (UFES); Itarana, Fazenda Bom Destino, 2 machos, armadilha Möricke, 7 machos, $19^{\circ} 50^{\prime} 40^{\prime \prime S} 40^{\circ} 54^{\prime} 31^{\prime \prime O}$, armadilha Möricke, (UFES); 1 macho, Itaguaçu, Fazenda Bom Destino, 1904'50"S 4054'31"O, 21 24.ii.2004, armadilha Möricke, B. C. Araújo col. (UFES).

Variações: cabeça e dorso torácico com reflexos verde-oliva e dourados fortes; clípeo com lobo mediano sub-angulado; carena occipital não-visível em vista dorsal; dorso torácico coriáceo; disco pronotal com carena lateral fina e bem definida.

Discussão. Esta espécie é similar a A. rectus Santos \& Azevedo, 2000, por ter mandíbula com cinco dentes; clípeo com lobo mediano angulado; relação comprimento/largura dos quatro primeiros segmentos antenais; escrobo antenal com carena muito tênue, não atingindo a margem interna do olho; fronte coriácea; índices WH/LH, WF/WH, WF/HE, WOT/OOL, VOL/HE semelhantes, mesopleura pouca coriácea e difere por ter carena occipital pouco visível em vista dorsal; disco pronotal com carena lateral bem fraca e inconspícua; notáulice fina com extremidade distal convergente; mesopleura com fóvea inferior com margem superior totalmente aberta; parâmero 3,33x mais longo que largo, com reentrância acentuada na metade basal da margem ventral, enquanto que A. rectus tem disco pronotal com carena lateral bem definida; notáulice bem grossa e dilatada na extremidade posterior; mesopleura com fóvea inferior com margem superior aberta no terço posterior; parâmero 3,08x mais longo que largo; metade basal da margem ventral uniforme.

Distribuição. Brasil (Espírito Santo).

Etimogenia. Do latim artus: estreito, em referência à base do parâmero muito estreita.

\section{Anisepyris basilargus Santos sp. nov.} (Figs. 14-18)

Descrição. Holótipo: macho; comprimento 4,50 mm; LFW $2,60 \mathrm{~mm}$.

Coloração. Cabeça e dorso torácico pretos; cabeça com reflexos verde-escuros tênues; mesossomo preto; metassomo e clípeo castanho-escuros; mandíbula preta exceto terço distal castanho-avermelhado; palpos e escapo castanho-escuros; pedicelo quase preto; coxas, trocânteres, fêmures e tarsos castanho-avermelhados; tíbias castanho-claras; asa anterior hialina; nervuras castanho-avermelhadas.

Cabeça (Fig. 14). Mandíbula com cinco dentes apicais, os superiores de mesmo tamanho e menores que os inferiores, mediano mais curto (Fig. 15). Clípeo com lobo mediano angulado, carena mediana alta e arqueada em perfil. Quatro primeiros segmentos antenais na proporção 14:5:4:9, relação comprimento/largura dos segmentos antenais: III 1,00x; III + $\mathrm{IV}=2,60 \mathrm{x} ; \mathrm{IV}=1,80 \mathrm{x} ; \mathrm{XI}=2,25 \mathrm{x}$. Escrobo antenal com carena distinta, margem posterior da carena acompanhada de um sulco foveolado em toda extensão. Olho com cerdas longas. Fronte fortemente coriácea, pontos médios, densos, distintos, separados por 0,5-1x seus diâmetros; WH 0,87x LH; WF 0,62x WH; WF 1,11x HE; WOT 0,80x OOL. Vértice levemente convexo, canto arredondado; carena occipital não visível em vista dorsal; VOL 0,4x HE.

Mesossomo (Fig. 14). Dorso torácico coriáceo, com pontos pequenos, distintos, separados 0,5-3x seus diâmetros. Disco pronotal 2,64x mais largo que longo; carena transversal anterior distinta e elevada; margem posterior da carena com sulco foveolado; carena lateral ausente; margem posterior do disco pronotal acompanhada de série de fóveas grandes e nítidas. Notáulice quase completa. Disco propodeal 1,07x mais largo que longo, cinco carenas discais bem distintas e duas carenas adicionais tênues paralelas à paramediana; canto posterior foveolado; lateral do propódeo predominantemente estrigulada e coriácea; declividade com estrias transversais distintas, carena mediana incompleta ventralmente. Mesopleura pouco brilhante, coriácea, com pontuações rasas; fóvea inferior com margem superior aberta e margem inferior fechada e com pontos grandes paralelos à margem inferior (Fig. 16). Fêmur anterior 3,00x mais longo que largo. Tíbia mediana sem espinhos dorsais. Garra tarsal bífida.

Genitália. (Figs. 17, 18). Parâmero tão longo quanto basiparâmero, 1,91x mais longo que largo; base alargada; margens apical larga e paralela, dorsal paralela e angulada próximo ao ápice, ventral convexa próximo ao ápice; ápice e margem ventral pilosos; cúspide com ramo dorsal estreito e afilado no ápice; ramo ventral digitiforme; dígito tão longo quanto a cúspide; edeago tão longo quanto o dígito; metade basal dilatada; metade apical estreita; margem apical arredondada.

Material Examinado. Holótipo: macho. BRASIL, Espírito Santo, Vitória, Parque Estadual da Fonte Grande, 20¹7'51,7'S 40²0'13,1"O, 09.ix.2000, varredura, Azevedo, Kawada \& Santos col. (UFES). Parátipos: BRASIL, Espírito Santo, 1 macho, mesmos dados do holótipo (UFES); Vitória, Parque Estadual da Fonte Grande, 2 machos, 24.xi.2000, 11 machos, 26.iii-30.vi.2001, (UFES); 1 macho, Santa Teresa, Estação Biológica de Santa Lúcia, 1958'18,5”S 40³2’07,6"O, 29.vi.2002, varredura, Azevedo \& Kawada col. (UFES); 2 machos, Pancas, Fazenda Juliberto Stur, 19²12'54,8"S 4047'52,5"O, 2431.i.2003, armadilha Malaise, M. T. Tavares, C. O. Azevedo \& eq. col. (UFES).

Variações: cabeça preta com reflexos metálicos verdes-oliva e dourados; disco pronotal com carena lateral bem fina; parâmero com ápice reto, margem dorsal reta e levemente convexo na margem ventral próxima ao ápice, ou margem dorsal e ventral com um chanfro, ou ápice arredondado, margem dorsal e ventral levemente convexas, ou ápice levemente convexo; cúspide com ramo dorsal um pouco alargado.

Discussão. Esta espécie tem cabeça alongada; terceiro segmento antenal tão longo quanto espesso; disco pronotal não marginado lateralmente; disco propodeal 1,07x mais largo 


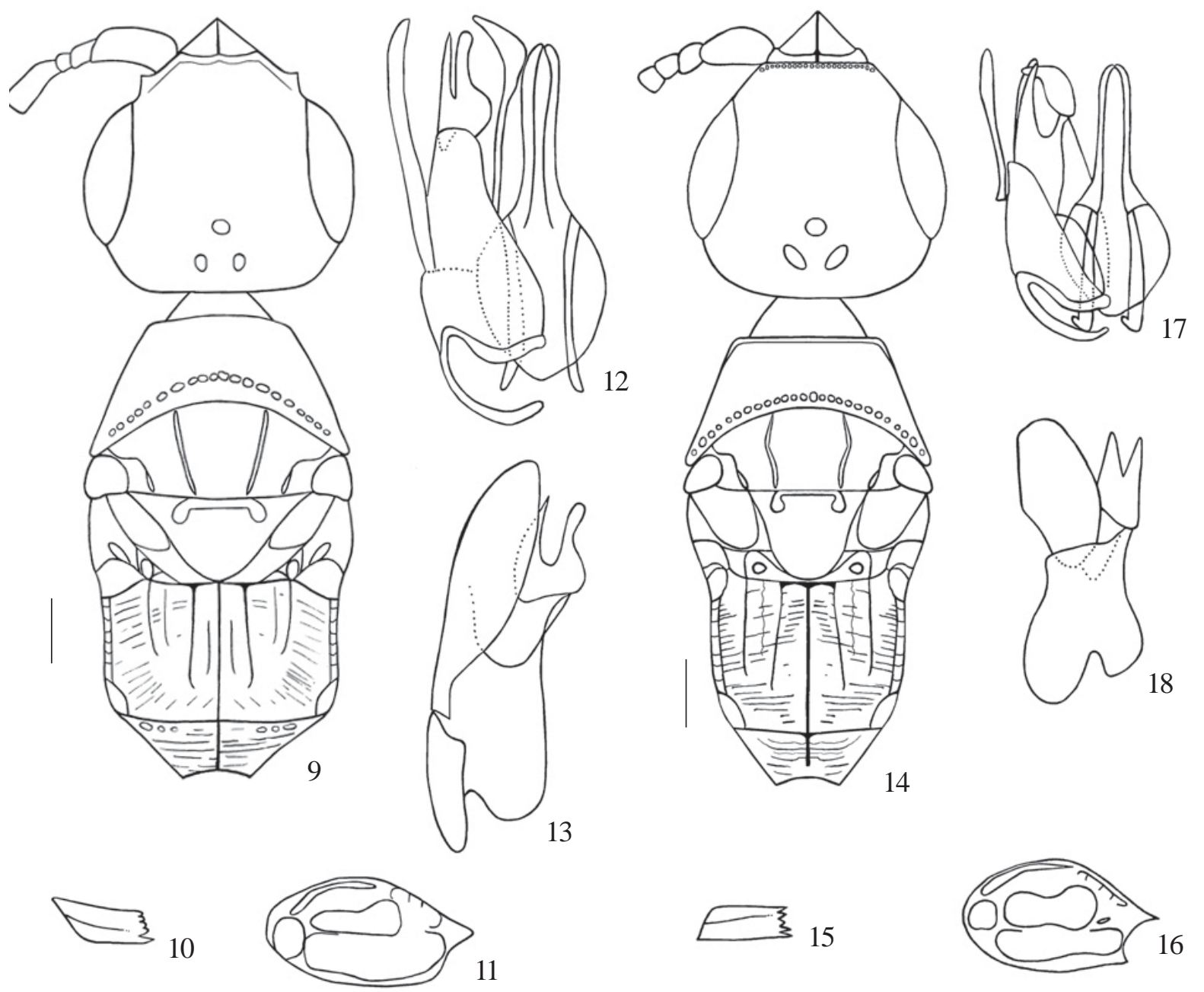

Figs. 9-18. Anisepyris artus Santos sp. nov., holótipo, macho. 9, cabeça e mesossomo, dorsal; 10, mandíbula, frontal; 11, mesopleura, lateral; 1213, genitália, ventral e lateral. Figs. 14-18. A. basilargus Santos sp. nov., holótipo, macho. 14, cabeça e mesossomo, dorsal; 15, mandíbula,

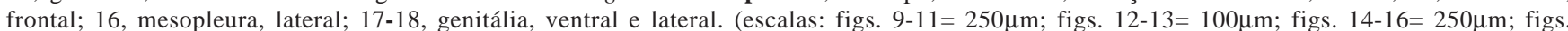
$17-18=100 \mu \mathrm{m})$.

que longo, o que permite sua inserção no grupo de espécies proteus. Chega ao ponto de A. metallicus Kieffer, 1905 e A ecuadorianus Evans, 1966 na chave de Evans (1966). Porém, A. metallicus tem disco pronotal com carena lateral e genitália com parâmero longo, cerca de $2 x$ mais longo que o basiparâmero; cúspide com ramo dorsal alargado e o ventral digitiforme; margem interna da volsela com lobo angulado e $A$. ecuadorianus tem disco propodeal 1,26x mais largo que longo; parâmero cerca de 1,5x o comprimento do basiparâmero; cúspide com ramo dorsal estreito no ápice, alargado na porção mediana e basal, ramo ventral digitiforme; margem interna da volsela com lobo truncado,enquanto A. basilargus sp. nov. tem disco pronotal com carena transversal anterior bem distinta, elevada e a lateral ausente; parâmero tão longo quanto o basiparâmero; cúspide com ramo dorsal estreito e afilado no ápice quando em vista ventral.

Distribuição. Brasil (Espírito Santo).

Etimogenia. Do latim basis: base + largus: larga, em referência à base do parâmero que é larga.

\section{Anisepyris bifidus Evans, 1966}

Esta espécie tem seus dados ampliados para o Espírito Santo e relatados os primeiros registros para Bahia, Rio de Janeiro, São Paulo e Paraná. Nesta série, foram encontradas as seguintes variações: cabeça e dorso torácico com reflexos azulados, clípeo com lobo mediano obtusamente angulado, escrobo antenal com carena inconspícua, fronte coriácea, vértice reto e carena occipital parcialmente visível em vista dorsal, conjunto de fóveas pouco definidas paralelas à margem posterior do disco pronotal, parâmero com ramo ventral pouco menor e cúspide com ramo dorsal castanho-escuro e ápice pouco mais largo que os exemplares analisados por Santos \& Azevedo (2000).

Material Examinado. BRASIL, Bahia, 2 machos, Porto Seguro, Estação Ecológica Pau Brasil, 16²3'17,6”'S 39¹0'55"O, 16.v.2002, varredura, C.O. Azevedo \& eq. col. (MZSP, UFES); Espírito Santo, 1 macho, Linhares, Povoação, Fazenda Benesfort, 19³7'00"'S $19^{\circ} 48^{\prime} 00 " O, 8-10 . x .2000$, varredura (UFES); 3 machos, Santa Maria 
de Jetibá, Fazenda Paulo Seick, 2002’31,1"S 4041’51,3"O, 29.xi13.xii-2002, armadilha Malaise, M. T. Tavares, C. O. Azevedo \& eq. col (UFES); 1 macho, Pancas, Fazenda Juliberto Stur, 19²12'54,8"S $40^{\circ} 47^{\prime} 52,5^{\prime \prime O}$, 24-31.i.2003, armadilha Malaise, M. T. Tavares, C. O. Azevedo \& eq. col (UFES); 1 macho, Santa Teresa, Estação Biológica de Santa Lúcia, 1958'25,2”S 40³1'44,6"O, 08.iv.2001, varredura, C. O. Azevedo \& eq. col. (MZSP), 1 macho, $19^{\circ} 58^{\prime} 00^{\prime \prime} \mathrm{S} 40^{\circ} 32^{\prime} 00^{\prime \prime O}$, 17.v.2002, 2 machos, 31.iv.2004, Azevedo \& Tavares col.(UFES); Rio de Janeiro, 1 macho, Santa Maria Madalena, Parque Estadual de

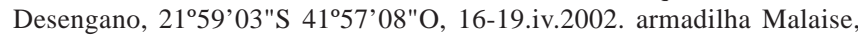
A. M. Penteado-Dias \& eq. col. (MZSP); São Paulo, 2 machos, Peruíbe,

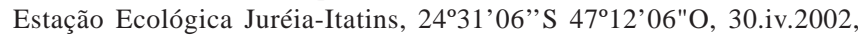
varredura, N. W. Perioto \& eq. col. (MZSP, UFES); Paraná, 1 macho, Antonina, Reserva Sapitanduva, 25²8'00"S 4850’00"O, 15.ii.1988, armadilha Malaise, Levantamento Entomológico Profaupar (DZUP); 3 machos, Morretes, Parque Estadual do Pau Oco, 25³4'27,5"S 4853'33"O, 09.iv.2002, varredura, M.T. Tavares \& eq. col. (MZSP, UFES).

Anisepyris bipartitus Santos \& Azevedo, 2000

Esta espécie é registrada pela primeira vez para Alagoas. Este material foi comparado com o holótipo de Manaus (AM) depositado no INPA. Nesta série, foram encontradas as seguintes variações: cabeça e dorso torácico verde-oliva com reflexos dourados, carena occipital visível ou pouco visível em vista dorsal, parâmero com base pouco mais longa que os exemplares analisados por Santos \& Azevedo (2000).

Material Examinado. BRASIL, Alagoas, 2 machos, Quebrangulo, Reserva Biológica da Pedra Talhada, 09¹4'54's 36²5'32'O, 11 14.ix.2002, armadilha Malaise, Penteado-Dias \& eq. col. (MZSP, UFES).

\section{Anisepyris cepus Santos sp. nov.} (Figs. 19-21)

\section{Descrição. Holótipo: fêmea; comprimento 5,50 mm; LFW} $2,60 \mathrm{~mm}$

Coloração. Cabeça e dorso torácico pretos, com reflexos verde-claros e dourados tênues no disco pronotal; porção mediana da fronte com reflexos verdes, dourados e róseos conspícuos; disco propodeal preto; metassomo preto; clípeo castanho-escuro quase preto; mandíbula, palpos, escapo, pedicelo e flagelo castanho-avermelhados; coxas castanhoclaras exceto coxa anterior castanho-escura; trocânteres e tíbia castanho-claros; fêmures e tarsos castanho-avermelhados exceto fêmur posterior castanho-escuro; asa anterior subialina e com duas faixas mais escuras; nervuras castanhoavermelhadas.

Cabeça (Fig. 19). Mandíbula com quatro dentes apicais largos, três superiores curtos (Fig. 20). Clípeo com lobo mediano angulado, carena mediana alta e arqueada em perfil. Quatro primeiros segmentos antenais na proporção de 20:6:5:6, relação comprimento/largura dos segmentos antenais: III 1,25x; $\mathrm{III}+\mathrm{IV}=2,20 \mathrm{x} ; \mathrm{IV}=1,00 \mathrm{x} ; \mathrm{XI}=1,00 \mathrm{x}$. Escrobo antenal carenado. Olho com cerdas longas. Fronte fortemente coriácea, pontos largos, rasos, separados por 1-2x seus diâmetros; WH 0,84x LH; WF 0,59x WH; WF 0,84x HE; WOT 0,86x OOL. Vértice ligeiramente convexo, canto arredondado; carena occipital não visível em vista dorsal; VOL 0,31x HE.
Mesossomo (Fig. 19). Disco pronotal brilhante e mesoscuto coriáceo; com pontos pequenos, distintos, separados $1-4 \mathrm{x}$ seus diâmetros. Disco pronotal 1,75x mais largo que longo; carena transversal anterior fraca, porém evidente; carena lateral inconspícua; margem posterior do disco pronotal acompanhada de série de fóveas rasas. Notáulice quase completa. Disco propodeal 1,16x mais longo que largo, com cinco carenas discais distintas, duas carenas adicionais fortes e completas paralelas à mediana e duas carenas adicionais fracas e incompletas posteriormente paralelas à paramediana; carena lateral acompanhada por sulco foveolado; canto posterior foveolado; lateral do propódeo predominantemente estrigulada e coriácea; declividade estrigulada, carena mediana incompleta ventralmente. Mesopleura coriácea; fóvea inferior com margem superior aberta e coberta por pontos rasos de tamanho variável, margem inferior fechada (Fig. 21). Fêmur anterior 2,00x mais longo que largo. Tíbia mediana com espinhos curtos. Garra tarsal bífida.

Material Examinado. Holótipo: fêmea. BRASIL, Espírito Santo, Atílio Vivácqua, Fazenda José Carlos Lustoza, 2055'57,6"S 41 ${ }^{\circ} 11^{\prime} 22,1^{\prime \prime} \mathrm{O}, 13-20 . i 1.2003$, armadilha Malaise, M. T. Tavares, C. O. Azevedo \& eq. col (UFES). Parátipo: BRASIL, Espírito Santo, 1 fêmea, Pancas, Fazenda Juliberto Stur, $19^{\circ} 13^{\prime} 10,5^{\prime \prime S} 40^{\circ} 46^{\prime} 23,8^{\prime \prime} \mathrm{O}$, 24-31.i.2003, armadilha Malaise, M. T. Tavares, C. O. Azevedo \& eq. col. (UFES).

Variação: cabeça e dorso torácico com reflexos dourados fortes.

Discussão. Esta espécie difere das demais por ter cabeça bastante alongada; mandíbula com quatro dentes distintos, não formando uma ampla lâmina cortante; disco pronotal com carena transversal anterior fraca; carena lateral fina e inconspícua; mesopleura coriácea, fóvea inferior com margem superior aberta e coberta por pontos rasos de tamanho variável. Mas quanto à genitália tem muita semelhança com outras espécies deste grupo. Quanto à morfologia externa (fronte coriácea; cabeça alongada e asa anterior com duas faixas mais escuras), assemelha-se a Rhabdepyris (Trichotepyris) superpilosus Azevedo, 1993.

Distribuição. Brasil (Espírito Santo).

Etimogenia. cepus: combinação aleatória de letras com desinência masculina.

\section{Anisepyris delicatus Evans, 1966}

Esta espécie teve ampliados os dados de distribuição para o Espírito Santo. Nesta série, foram encontradas as seguintes variações: clípeo com o lobo mediano com carena mediana alta e arqueada quando em perfil, carena anterior do disco pronotal inconspícua e as laterais ausentes, vértice quase reto ou levemente convexo, carena occipital não visível ou parcialmente visível em vista dorsal, parâmero com ápice mais estreito que da série tipo ou pouco mais curto, quase do mesmo tamanho da cúspide e do edeago, cúspide, dígito e edeago com ápice da mesma altura.

Material Examinado. BRASIL, Espírito Santo, Santa Teresa, 


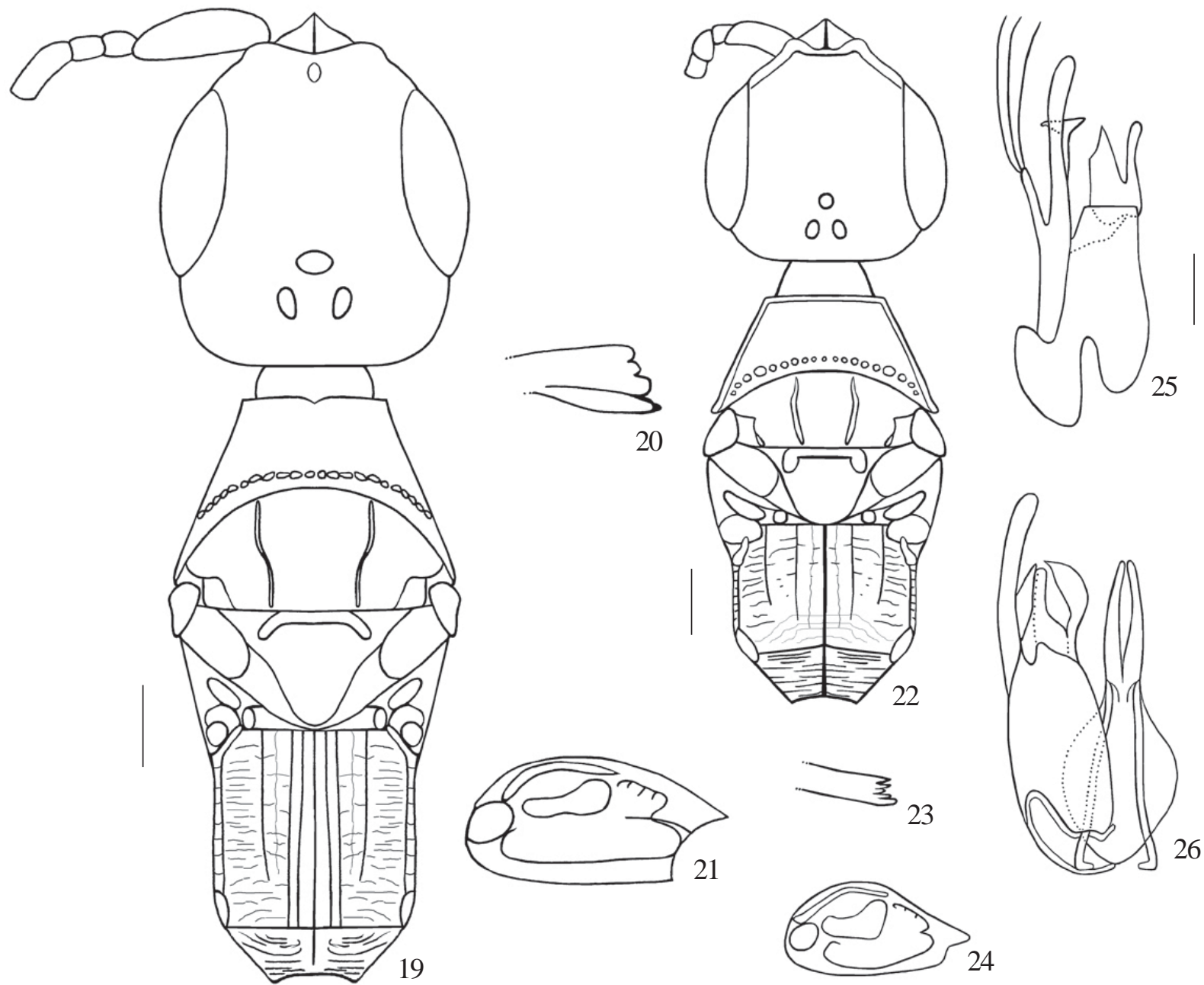

Figs. 19-26. Anisepyris cepus Santos sp. nov., holótipo, fêmea. 19, cabeça e mesossomo, dorsal; 20, mandíbula, frontal; 21, mesopleura, lateral. Figs. 22-26. A. ramosus Santos sp. nov., holótipo, macho. 22, cabeça e mesossomo, dorsal; 23, mandíbula, frontal; 24, mesopleura, lateral; 2526, genitália, lateral e ventral. (escalas: figs. $19-21=250 \mu \mathrm{m}$; figs. $22-24=250 \mu \mathrm{m}$; figs. $25-26=100 \mu \mathrm{m}$ ).

Estação Biológica de Santa Lúcia, 1958'10,5's 40³2'10,3'O, 3 machos, 06-12.iv.2001, armadilha Malaise, C. O. Azevedo \& eq. col (MZSP), 3 machos, $19^{\circ} 58^{\prime} 16,7^{\prime}$ 'S 40³2'06,9"O, (MZSP, UFES), 4 machos, $19^{\circ} 58^{\prime} 18,5^{\prime \prime} \mathrm{S} 40^{\circ} 32^{\prime} 07,6^{\prime \prime O}$, (MZSP, UFES), 2 machos, $19^{\circ} 58^{\prime} 37,3^{\prime \prime} \mathrm{S} 40^{\circ} 32^{\prime} 22,5^{\prime \prime O}$, (MZSP, UFES), 2 machos, 1958'19,5's $40^{\circ} 32^{\prime} 10,3^{\prime \prime O}$, (MZSP, UFES), 5 machos, 1958'25,'”S 40³1'44,6"O, varredura, (MZSP, UFES), 1 macho, 1958'36,0'"S 40³2'06,4"O, (MZSP), 1 macho, 1958'39,2"'S 40³2'06,6"O, (MZSP, UFES), 2 machos, Santa Maria de Jetibá, Fazenda Paulo Seick, 2002'31,1"S $40^{\circ} 41^{\prime} 51,3 " \mathrm{O}, 29 . x \mathrm{i}-13 . x \mathrm{ii} .2002$, armadilha Malaise, M. T. Tavares, C. O. Azevedo \& eq. col. (UFES).

\section{Anisepyris dentatus Santos \& Azevedo, 2000}

Esta espécie é registrada pela primeira vez para Pernambuco, Bahia, Espírito Santo e Paraná. Este material foi comparado com o holótipo de Tucuruí (PA) depositado no MPEG. Nesta série, foram encontradas as seguintes variações: clípeo com lobo mediano sub-angulado e escrobo antenal fortemente carenado, carena atingindo metade da margem interna do olho, cúspide e dígito com mesma altura e edeago pouco maior que dígito ou ramo dorsal não tão estreito no ápice ou dígito e edeago de mesma altura ou dígito pouco mais alto que edeago e cúspide.

Material Examinado. BRASIL, Pernambuco, Recife, Parque Dois Irmãos, $08^{\circ} 00^{\prime} 37,7^{\prime \prime}$ S $34^{\circ} 56^{\prime} 31^{\prime \prime O}, 3$ machos, armadilha Malaise, 1 macho, armadilha Möricke, 1 macho, varredura, 17-22.vii.2002, STP Amarante \& eq. col. (MZSP, UFES); Bahia, 3 machos, Porto Seguro, Estação Ecológica Pau Brasil, 16²3'17,6''S 39¹0'55"O, 1617.v.2002, varredura, C. O. Azevedo \& eq. col. (MZSP, UFES); Espírito Santo, 1 macho, Sooretama, Reserva Biológica de Sooretama, $19^{\circ} 00^{\prime} 11,5$ 'S 4007'08"O, 06.iv.2002, varredura, C. O. Azevedo \& eq. col.(MZSP); 1 macho, Pancas, Fazenda Juliberto Stur, $19^{\circ} 12^{\prime} 54,8^{\prime \prime S}$ $40^{\circ} 47^{\prime} 52,5^{\prime \prime O}$, 24-31.i.2003, armadilha Malaise, M. T. Tavares, C. O. Azevedo \& eq. col. (UFES); Paraná, 1 macho, Jundiaí do Sul, Fazenda Monte Verde, 2326'00"S 50¹6'00"O, 17.xi.1986, armadilha Malaise, Levantamento Entomológico Profaupar (DZUP).

\section{Anisepyris divisus Santos, 2002}

Esta espécie tem seus dados de distribuição ampliados para o Espírito Santo. Este material foi comparado com o holótipo de Castelo (ES) depositado na UFES. Nesta série, 
foram encontradas as seguintes variações: vértice quase reto, carena occipital pouco visível em vista dorsal.

Material Examinado. BRASIL, Espírito Santo, 1 macho, Pancas, Fazenda Juliberto Stur, $19^{\circ} 12^{\prime} 54,8^{\prime \prime} \mathrm{S} 40^{\circ} 47^{\prime} 52,5^{\prime \prime O}, 24-31 . i .2003$, armadilha Malaise, M. T. Tavares, C. O. Azevedo \& eq. col. (UFES); 1 macho, Linhares, Povoação, Fazenda Benesfort, 19³7'00'"S 1948'00"O, 08-10.x.2000, (UFES).

\section{Anisepyris inconspicuus Santos, 2002}

Esta espécie era conhecida apenas pelo holótipo, com este estudo são ampliados os dados de distribuição para o Espírito Santo. Este material foi comparado com o holótipo de Castelo (ES) depositado na UFES. Nesta série, foram encontradas as seguintes variações: mandíbula com terceiro dente menor que outros; fóvea inferior da mesopleura com margem inferior fechada, parâmero mais estreito e ápice não tão angulado, margem ventral menos arqueada; cúspide com ramos dorsal e ventral com manchas escuras no ápice.

Material Examinado. BRASIL, Espírito Santo, 1 macho, Santa Maria de Jetibá, Fazenda Clarindo Kruger, 2004'27,9"S 4044’51,3"O, 29.xi-06.xii.2002, armadilha Malaise, M. T. Tavares, C. O. Azevedo \& eq. col. (UFES); Santa Teresa, Estação Biológica de Santa Lúcia, 0612.iv.2001, armadilha Malaise, C. O. Azevedo \& eq. col., 2 machos, $19^{\circ} 58^{\prime} 18,5^{\prime \prime S} 40^{\circ} 32^{\prime} 07,6$ "O, (MZSP), 1 macho, 1958'18,6" S $40^{\circ} 32^{\prime} 08,8^{\prime \prime O},(\mathrm{MZSP}) ; 1$ macho, $19^{\circ} 58^{\prime} 16,7^{\prime}$ 'S 40³2'06,9"O, (MZSP), 1 macho, 1958'37,3'"S 40³2'22,5"O, (MZSP, UFES), 1 macho, 1958'19,5"'S 40³2'10,3"O, (MZSP), 1 macho, 1958'25,2"S 40³1'44,6"O, varredura, (MZSP, UFES).

\section{Anisepyris lobatus Santos \& Azevedo, 2000}

Esta espécie é registrada pela primeira vez para Pernambuco, Bahia e Paraná. Este material foi comparado com o holótipo de Cariacica (ES) depositado na UFES. Nesta série, foram encontradas as seguintes variações: vértice levemente convexo e carena occipital não visível em vista dorsal, mesopleura com fóvea inferior fechada no terço posterior da margem inferior, cúspide, dígito e edeago de mesma altura, parâmero com margem dorsal pouco angulada próximo ao ápice, margem apical mais arredondada que da série tipo.

Material Examinado. BRASIL, Pernambuco, 1 macho, Recife,


armadilha Malaise, STP Amarante \& eq. col. (MZSP); Bahia, 1 macho, Porto Seguro, Estação Ecológica Pau Brasil, 16²3'17,6"S 39¹0'55"O, 17.v.2002, armadilha Malaise, C. O. Azevedo \& eq. col. (MZSP); Espírito Santo, 4 machos, Santa Teresa, Estação Biológica de Santa Lúcia, 1958'19,5"S 40³2'10,3"O, 06-13.iv.2001, armadilha Malaise, C. O. Azevedo \& eq. col. (MZSP, UFES); Paraná, 1 macho, Jundiaí do Sul, Fazenda Monte Verde, 23²6’00"S 50¹6’00"O, 11.i.1988, armadilha Malaise, Levantamento Entomológico Profaupar (DZUP).

\section{Anisepyris proteus Evans, 1966}

Esta espécie tem ampliados os dados de distribuição geográfica para São Paulo e Paraná. Os exemplares fêmeas foram comparados com o holótipo de Bocaiúva (PR) depositado no MCZH. Nesta série, foram encontradas as seguintes variações nos machos: cabeça e dorso torácico dourados, fronte pouco coriácea, margem posterior do disco pronotal acompanhada de uma série de fóveas fracas e pouco definidas, carena lateral do disco pronotal presente na metade anterior do disco, carena lateral do disco pronotal bem fraca, mesopleura coriácea, parâmero com margem ventral mais arredondada que da série tipo ou levemente aguda, margem apical levemente arredondada, porção basal da margem ventral quase reta, cúspide com invaginação rasa dividindo os ramos dorsal e ventral ou com invaginação profunda dividida em ramo dorsal e ramo ventral, ápice do ramo dorsal mais estreito ou cúspides distantes, cúspide, dígito e edeago de mesma altura; edeago pouco mais alto que o dígito ou pouco mais baixo.

Material Examinado. BRASIL, Espírito Santo, 3 machos, Santa Maria de Jetibá, Fazenda Paulo Seick, 2002'31,1"S 4041'51,3"O, 29.xi-06.xii.2002, armadilha Malaise, M. T. Tavares, C. O. Azevedo \& eq. col. (UFES); 1 macho, mesmos dados anteriores exceto Fazenda Clarindo Kruger, $20^{\circ} 04^{\prime} 27,9^{\prime \prime S} 40^{\circ} 44^{\prime} 51,3^{\prime \prime} \mathrm{O}$, (UFES); 2 machos, Santa Teresa, Estação Biológica de Santa Lúcia, 1958'18,5”S 40³2’07,6"O, 6-12.iv.2001, armadilha Malaise, C. O. Azevedo \& eq. col. (MZSP), 4 machos, 1958'25,2''S 40³1'44,6"O, varredura, (MZSP, UFES), 1 macho, 1958'36's 40³2'06,4"O, varredura, (MZSP), 1 macho, $19^{\circ} 58^{\prime} 19,5^{\prime \prime} \mathrm{S} 40^{\circ} 32$ '10,3"O, armadilha Malaise, (MZSP, UFES), 1 macho, 1958'10,5''S 40³2'10,3"O, armadilha Malaise, (MZSP); São Paulo, Ribeirão Grande, Parque Estadual Intervales, $24^{\circ} 18^{\prime} 16^{\prime \prime S}$ 4821'53"O, 10-14.xii.2000, 1 fêmea, armadilha Möricke, 9 machos, armadilha Malaise, M. T. Tavares \& eq. col. (MZSP, UFES); Salesópolis,

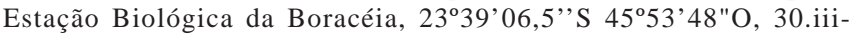
02.iv.2001, 1 macho, armadilha Malaise, 2 machos, varredura, STP Amarante \& eq. col. (MZSP, UFES); 1 macho, Peruíbe, Estação Ecológica Juréia-Itatins, $24^{\circ} 31^{\prime} 06^{\prime}$ 'S $47^{\circ} 12^{\prime} 06^{\prime \prime O}$, 6.v.2002, armadilha Malaise, N. W. Perioto \& eq. col. (MZSP); Paraná, Morretes, Parque Estadual do Pau Oco, 25³4'27,5"S 4853'33"O, 07-11.iv.2002, 1 fêmea, armadilha Möricke, 2 machos, armadilha Malaise, 1 macho, varredura, M. T. Tavares \& eq. col. (MZSP, UFES); 1 macho, Fênix,

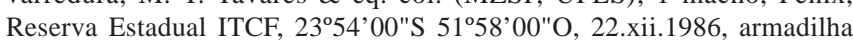
Malaise, Levantamento Entomológico Profaupar (DZUP).

\section{Anisepyris ramosus Santos sp. nov.} (Figs. 22-26)

Descrição: Holótipo: macho; comprimento 4,14 mm; LFW $2,44 \mathrm{~mm}$.

Coloração. Cabeça e dorso torácico pretos, com reflexos verdes-oliva e dourados tênues; metassomo castanho-escuro quase preto; clípeo e escapo castanho-escuros; mandíbula, pedicelo e flagelo castanho-avermelhados; coxas castanhoescuras quase pretas; palpos, trocânteres e tíbias castanhoclaros; fêmures e tarsos castanho-avermelhados; asa anterior hialina; nervuras castanho-avermelhadas.

Cabeça (Fig. 22). Mandíbula com cinco dentes apicais, mediano menor e inferior maior (Fig. 23). Clípeo com lobo mediano angulado, carena mediana alta e arqueada em perfil. Quatro primeiros segmentos antenais na proporção de 13:5:2:9, relação comprimento/largura dos segmentos antenais: III 0,66x; $\mathrm{III}+\mathrm{IV}=2,75 \mathrm{x} ; \mathrm{IV}=2,25 \mathrm{x} ; \mathrm{XI}=3,00 \mathrm{x}$. Escrobo antenal com carena distinta, não atingindo a margem interna do olho. Olho com cerdas longas. Fronte pouco coriácea com pontos distintos e separados 1-3x seus diâmetros; WH 1,06x LH; WF 0,60x WH; 
WF 1,11x HE; WOT 1,50x OOL. Vértice quase reto, canto arredondado; carena occipital não visível em vista dorsal; VOL $0,19 \times \mathrm{HE}$

Mesossomo (Fig. 22). Dorso torácico coriáceo, com pontos pequenos e esparsos; disco pronotal 2,13x mais largo que longo; carena transversal anterior distinta; carena lateral distinta, margem posterior do disco pronotal acompanhada de série de fóveas grandes. Notáulice quase completa. Disco propodeal 1,33x mais largo que longo, com cinco carenas discais distintas e duas carenas adicionais tênues e incompletas anteriormente, paralelas à mediana; canto posterior foveolado; lateral do propódeo predominantemente estrigulada e coriácea, declividade com a metade superior coriácea e metade inferior estrigulada, carena mediana completa. Mesopleura brilhante, pouco coriácea, com pontos esparsos; fóvea inferior com margem superior aberta e margem inferior fechada (Fig. 24). Fêmur anterior 2,60x mais longo que largo. Tíbia mediana sem espinhos dorsais. Garra tarsal trífida.

Genitália. (Figs. 25-26). Parâmero longo, cerca de 2,41x basiparâmero, 3,72x mais longo que largo; parâmero profundamente bifurcado, formando dois ramos estreitos, dorsal com ápice arredondado e $0,32 \mathrm{x}$ comprimento do ramo ventral, com três cerdas apicais muito longas e ramo ventral longo, com ápice ligeiramente voltado para dentro e diversas cerdas no terço apical; cúspide profundamente bifurcada, com ramo dorsal pouco alargado e estreitado em direção ao ápice; ramo ventral digitiforme; dígito tão longo quanto à cúspide; edeago tão longo quanto o dígito; metade basal dilatada; metade apical estreita; margem apical arredondada.

Material Examinado. Holótipo: macho. BRASIL, Bahia, Porto Seguro, Estação Ecológica Pau Brasil, 16²23'17,6”'S 39²10'55"O, 16.v.2002, varredura, C. O. Azevedo e eq. col (MZSP). Parátipos: BRASIL, Bahia, 5 machos, mesmos dados do holótipo (MZSP, UFES); Alagoas, 6 machos, Quebrangulo, Reserva Biológica da Pedra Talhada, 09 14 '54' 'S 36 $25^{\prime} 32^{\prime \prime}$ O, 11-14.ix.2002, armadilha Möricke, PenteadoDias \& eq. col. (MZSP, UFES); Sergipe, 1 macho, Santa Luzia do Itanhy, Crasto, $11^{\circ} 22^{\prime} 37,4^{\prime \prime} S$ 37²4'50,3"O, 01-04.viii.2002, armadilha Malaise, M. T. Tavares \& eq. col. (MZSP).

Variações: cabeça e dorso torácico com reflexos verdeclaros e dourados fortes; carena occipital parcialmente visível em vista dorsal; disco pronotal com carenas laterais inconspícuas; mesopleura coriácea.

Discussão. Esta espécie é semelhante a A. bipartitus Santos \& Azevedo, 2000, por ter mandíbula com cinco dentes; clípeo com lobo mediano angulado; fronte pouco coriácea; dorso torácico coriáceo, pontos pequenos e esparsos; disco pronotal carenado anterior e lateralmente; mesopleura com fóvea inferior aberta na margem superior e fechada na inferior e o parâmero bifurcado mas difere desta por ter asa anterior hialina; escrobo antenal com carena distinta porém, não atingindo a margem interna do olho; carena occipital não visível em vista dorsal; mesopleura pouco coriácea; parâmero com ramo dorsal com ápice arredondado e $0,32 \mathrm{x}$ comprimento do ramo ventral, com três cerdas apicais muito longas; ramo ventral longo, ápice ligeiramente voltado para dentro enquanto $A$. bipartitus tem asa anterior sub-hialina; escrobo antenal com carena inconspícua e prolongada medianamente; carena occipital tênue parcialmente visível em vista dorsal; mesopleura coriácea; parâmero com ramo dorsal com ápice afilado e 0,60x comprimento do ramo ventral, com uma cerda apical muito longa; ramo ventral longo, ápice reto.

Distribuição. Brasil (Alagoas, Sergipe, Bahia).

Etimogenia. Do latim ramosus: ramo, em referência aos ramos do parâmero.

\section{Anisepyris similis Santos \& Azevedo, 2000}

Esta espécie é registrada pela primeira vez para Sergipe, Bahia e Rio de Janeiro. Os exemplares estudados foram comparados com o holótipo de Oriximiná (PA) depositado no INPA. Nesta série, foram observadas as seguintes variações: escrobo antenal com carena distinta prolongada medianamente, fóvea inferior da mesopleura com carena vertical fraca, quase imperceptível.

Material Examinado. BRASIL, Sergipe, 1 macho, Santa Luzia do Itanhy, Crasto, $11^{\circ} 22^{\prime} 37,4^{\prime \prime} S$ 37 $24^{\prime} 50,3$ "O, 01-04.viii-2001, armadilha Malaise, M. T. Tavares \& eq. col. (MZSP); Bahia, 2 machos, Mata de São João, Reserva de Sapiranga, 12³3'36,4's 3802'57,2"O, 19-22.vii.2001, M. T. Tavares \& eq. col. (MZSP, UFES); Rio de Janeiro, 1 macho, Santa Maria Madalena, Parque Estadual de Desengano, $21^{\circ} 59^{\prime} 03^{\prime \prime S ~} 41^{\circ} 57^{\prime} 08^{\prime \prime O}$, 16-19.iv.2002, armadilha Malaise, A. M. Penteado-Dias \& eq. col. (MZSP).

\section{Anisepyris triangularis Moreira \& Azevedo, 2003}

Esta espécie é registrada pela primeira vez para Alagoas e Bahia. Os exemplares estudados foram comparados com o holótipo de Santa Teresa (ES) depositado na UFES. Nesta série, foram encontradas as seguintes variações: cabeça e dorso torácico pretos com reflexos verdes e dourados tênues ou com reflexos dourados, mandíbulas pretas com dentes castanho-avermelhados ou mandíbulas castanhoavermelhadas, antenas castanho-escuras, clípeo com lobo mediano sub-angulado ou angulado; carena do escrobo antenal distinta, um exemplar de Quebrangulo com essa estrutura paralela à margem interna do olho, atingindo aproximadamente metade de seu tamanho; fóvea inferior anterior da mesopleura com margem superior aberta no terço mediano, fóvea inferior posterior da mesopleura com margem anterior aberta em um pequeno espaço, parâmero com ápice arredondado ou margem dorsal levemente inclinada, cúspide estreita, com ramos dorsal e ventral digitiformes de mesmo tamanho ou invaginação profundamente emarginada e ramo ventral digitiforme maior que ramo dorsal, sendo este largo e afilado no ápice ou ramo ventral e dorsal de mesmo tamanho.

Material Examinado. BRASIL, Alagoas, 5 machos, Quebrangulo, Reserva Biológica da Pedra Talhada, 09²14'54' S 36²5'32"O, 08 14.ix.2002, armadilha Malaise, Penteado-Dias \& eq. col. (MZSP, UFES); Bahia, 3 machos, Porto Seguro, Estação Ecológica Pau Brasil, $16^{\circ} 23^{\prime} 17,6^{\prime \prime}$ S 39¹0'55"O, 16.v.2002, varredura, C. O. Azevedo \& eq. col. (MZSP, UFES); 1 macho, Una, $15^{\circ} 18^{\prime} 00^{\prime \prime} \mathrm{S} 39^{\circ} 04^{\prime} 00^{\prime \prime O}$, 12.vi.1997, armadilha Malaise, H. J. dos Santos col. (CEPLAC); Espírito Santo, 1 macho, Sooretama, Reserva Biológica de Sooretama, 
$19^{\circ} 00^{\prime} 11,5^{\prime \prime} \mathrm{S} 40^{\circ} 07^{\prime} 08^{\prime \prime O}, 22$. iii.2002, varredura, C. O. Azevedo \& eq. col (MZSP); 3 machos, Santa Teresa, Estação Biológica de Santa Lúcia, 1958'18,5'S 40³2'07,6"O, 07-10.iv.2001, varredura, C. O. Azevedo \& eq. col. (MZSP, UFES); 1 macho, Santa Teresa, Rio 15 de Agosto, $19^{\circ} 46^{\prime} 00^{\prime \prime S} 40^{\circ} 36^{\prime} 00^{\prime \prime O}, 24-25 . i i .2004$, armadilha Malaise, Lanes \& Redighieri col. (UFES); 3 machos, Atílio Vivácqua, Fazenda


armadilha Malaise, M. T. Tavares, C. O. Azevedo \& eq. col. (UFES).

\section{Anisepyris trinitatis Evans, 1966}

Esta espécie é registrada pela primeira vez para Alagoas. Este material foi comparado com exemplares do Maranhão (MA) depositados na UFES. Nesta série, foram encontradas as seguintes variações: asas anteriores hialinas, nervuras castanho-claras, clípeo com lobo mediano angulado.

Material Examinado. BRASIL, Alagoas, 1 macho, Quebrangulo, Reserva Biológica da Pedra Talhada, 09¹4'54'S 36²5'32"O, 11.ix.2002, varredura, Penteado-Dias \& eq. col. (MZSP).

\section{Anisepyris tuberosus Santos \& Azevedo, 2000}

Esta espécie é registrada pela primeira vez para Alagoas e Bahia. O material estudado foi comparado com o holótipo de Cariacica (ES) depositado na UFES. Nesta série, foram encontradas as seguintes variações: asas anteriores hialinas, escrobo antenal com carena distinta prolongada medianamente, fronte pouco coriácea com pontos pequenos e esparsos, carena occipital visível em vista dorsal, mesopleura fortemente coriácea, parâmero com margem apical quase reta ou ligeiramente mais estreito que da série tipo.

Material Examinado. BRASIL, Alagoas, 1 macho, Quebrangulo, Reserva Biológica da Pedra Talhada, 09¹4'54'S 36²5'32"O, 1114.ix.2002, armadilha Möricke, Penteado-Dias \& eq. col. (MZSP, UFES); Bahia, 1 macho, Porto Seguro, Estação Ecológica Pau Brasil, $16^{\circ} 23^{\prime} 17,6^{\prime \prime} \mathrm{S} 39^{\circ} 10^{\prime} 55^{\prime \prime O}$, 18.v.2002, armadilha Möricke, C. O. Azevedo \& eq. col. (MZSP); Espírito Santo, 1 macho, Cariacica, Reserva Biológica Duas Bocas, $20^{\circ} 17^{\prime} 00^{\prime \prime S} 40^{\circ} 28^{\prime} 00^{\prime \prime O}$, 29.i.1997, varredura, H. Santos Sá col. (UFES); 1 macho, Vila Velha, Reserva Jacarenema, $20^{\circ} 26^{\prime} 00^{\prime \prime S} 40^{\circ} 20^{\prime} 00^{\prime \prime} \mathrm{O}, 30 . x .2002$, armadilha Malaise, Azevedo \& eq. col (UFES); 1 macho, Pancas, Fazenda Juliberto Stur, 19²12'54,8"S $40^{\circ} 47^{\prime} 52,5^{\prime \prime} \mathrm{O}, 24-31 . i .2003$, armadilha Malaise, M. T. Tavares, C. O. Azevedo \& eq. col. (MZSP).

\section{Grupo venustus} Anisepyris rotundus Santos, 2002

Esta espécie é registrada pela primeira vez para Bahia, Rio de Janeiro e São Paulo e são ampliados os dados de distribuição para o Espírito Santo. Este material foi comparado com o holótipo de Castelo (ES) depositado na UFES. Nesta série, foram encontradas as seguintes variações: fronte e dorso torácico com reflexos dourados, fronte com pontos grandes, fóvea inferior da mesopleura com a metade posterior com margem superior fechada.
Material Examinado. BRASIL, Bahia, Ilhéus, Mata Esperança, 144' 'S 3904'W, 15-21.v.2002, 1 fêmea, armadilha Malaise, 3 fêmeas, armadilha Möricke, A. M. Penteado-Dias \& eq. col. (MZSP, UFES); 3 fêmeas, Una, 12.vi.1997, armadilha Malaise, H. J. dos Santos col. (CEPLAC, UFES); Espírito Santo, 1 fêmea, Atílio Vivácqua, Fazenda José Carlos Lustoza, 2055'57,6"S 41¹1'22,1"O, 20-27.ii.2003, armadilha Malaise, M. T. Tavares, C. O. Azevedo \& eq. col. (UFES); 1 fêmea, Santa Maria de Jetibá, Fazenda Clarindo Kruger, 2044'51,3"O, 06-13.xii.2002, armadilha Malaise, M. T. Tavares, C. O. Azevedo \& eq. col. (UFES); Rio de Janeiro, Nova Iguaçu, Reserva Biológica do

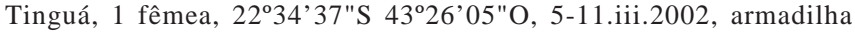
Malaise, STP Amarante \& eq. col. (MZSP), 1 fêmea, 22³4'28"S 4326'10.7"O, (MZSP, UFES); São Paulo, 1 fêmea, Ubatuba, Parque

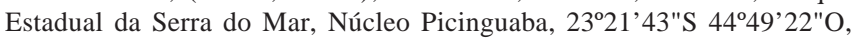
24-27.i.2002, armadilha Malaise, N. W. Perioto \& eq. col. (MZSP).

Agradecimentos. Aos curadores de coleções científicas e museus pelo empréstimo do material; ao Programa BIOTA/FAPESP (processo $\mathrm{n}^{\circ} 98 / 05083-0$ ), ao CNPq (processos $\mathrm{n}^{\circ}$ 469321/00-8, 303216/20042, 306231/2007-7), ao FACITEC/PMV (processo ${ }^{\circ} 004 / 2000$ ), pelo apoio financeiro para as coletas, tratamento do material e bolsa de Produtividade em Pesquisa do segundo autor; à CAPES pela concessão da bolsa de mestrado da primeira autora.

\section{REFERÊNCIAS}

Azevedo, C. O. 1993. On Rhabdepyris Kieffer (Hymenoptera, Bethylidae) in the area São Carlos, State of São Paulo, Brazil: II. Subgenus Trichotepyris. Revista Brasileira de Entomologia 37: 305-308.

Azevedo, C. O. 1999. Revision of the neotropical Dissomphalus Ashmead, 1893 (Hymenoptera, Bethylidae) with median tergal processes. Arquivos de Zoologia 35: 301-394.

Evans, H. E. 1959. The genus Anisepyris in America North of Mexico (Hymenoptera, Bethylidae). Proceedings of the Entomological Society of Washington 61: 97-120.

Evans, H. E. 1964. A synopsis of the American Bethylidae (Hymenoptera, Aculeata). Bulletin of the Museum of Comparative Zoology 132: 1-222.

Evans, H. E. 1966. A Revision of the Genus Anisepyris Kieffer (Hymenoptera, Bethylidae). Studia Entomologica 9: 1-120.

Gordh, G. \& L. Móczár 1990. A catalog of the world Bethylidae (Hymenoptera). Memoirs of the American Entomological Institute 46: 1-364.

Harris, R. A. 1979. A glossary of surface sculpturing. Occasional Papers in Entomology 28: 1-31.

Kieffer, J. J. 1905a. Description de nouveaux Hyménoptères. Annales de la Société Scientifique de Bruxelles 30: 113-178.

Kieffer, J. J. 1905b. Description de nouveaux Hyménoptères exotiques. Bulletin de la Société d'Historie Naturelle de Metz 24: 85114.

Moreira, A. R. \& C. O. Azevedo. 2003. Taxonomy of Anisepyris (Hymenoptera, Bethylidae) from Estação Biológica de Santa Lúcia, Santa Teresa, ES, Brazil. Boletim Museu Biologia Mello Leitão 15: $35-39$.

Santos, H. S. 2002. Species of Anisepyris Kieffer, 1905 (Hymenoptera, Bethylidae) collected in Cachoeira da Fumaça and Forno Grande State Parks, Espírito Santo, Brazil. Revista Brasileira de Entomologia 46: 243-249.

Santos, H. S. \& C. O. Azevedo. 2000. Sistemática das espécies de Anisepyris Kieffer, 1905 (Hymenoptera, Bethylidae) do Brasil. Revista Brasileira de Entomologia 44: 129-165.

Westwood, J. O. 1874. Thesaurus Entomologicus Oxoniensis. Oxford, Clarendon, 205p, 40 pls. 